\title{
Effect of Ankle Joint Inversion Trauma on Common Peroneal Nerve MCV.
}

\author{
Z. Mowafy Emam Mowafy*, Wafaa H. Borhan* And Akef A Khowailed** \\ * Physical Therapy department for surgery, Faculty of Physical Therapy, Cairo University, Egypt. \\ ** Physiology department, Faculty of Medicine, Cairo University, Egypt.
}

\begin{abstract}
This study has been conducted to determine effect of ankle joint inversion trauma on common peroneal nerve motor conduction velocity (MCV). Twenty patients ( 8 males and 12 females) who were 30 to 45 years of age $(X=33.75 \pm 1.15)$ participated in this study. They received the same medical care and manual tests for the inversion trauma. The involved lower limbs were considered the experimental group, while the normal contralateral lower limbs were considered the control group for all the twenty patients. Measurements of the MCV were carried out 10 days post trauma as a first record and one month post trauma as a second record for the both groups. Data collected for the first record showed that averages of MCV $(\mathrm{m} / \mathrm{sec})$, were $29.50 \pm 2.14$ and $42.45 \pm 3.08$ for the experimental and control groups respectively. While data collected for the second record showed that averages of MCV $(\mathrm{m} / \mathrm{sec})$, were $31.02 \pm 2.25$ and $42.80 \pm 3.11$ for the experimental and control groups respectively. Results showed a highly significant reduction in MCV for the first record in the experimental group, and in the second record for the experimental group, MCV was still significantly reduced. Results of this study support the hypothesis that inversion ankle trauma is frequently accompanied by peroneal nerve lesions. Also suggest that MCV measurements can be a valuable tool in evaluating more objectively the functional instability of the ankle joint.
\end{abstract}

\section{Introduction}

The most common painful injury to the ankle joint is sprain, this injury may vary from a simple strain in which the ligaments are merely elongated with

Minimal microtrauma to serious tearing of the ligamentous fibres with or without avulsion of the bones to which they attach, ${ }^{5.8 .11 .15}$.

The severity of a sprain is so frequently unrecognized that the statement of Watson - Jones must be heeded "It is worse to sprain an ankle than to break it." This implies that fracture receives adequate treatment and sprain is neglected or receive inappropriate care, ${ }^{2.410 .14}$.

The most common ligamentous injury occurs to the ankle lateral ligaments from inversion stress, most epidemiological studies report that approximately $95 \%$ of all ankle sprains are lateral and occur when foot is a plantar flexed and inverted position at the time of injury, when forces applied exceed a critical level, lateral capsular and ligamentous structures are injured, ${ }^{13.7 .13}$.

Various degrees of sprain-may occur, the ligament may be over-stretched (strained) without disruption of the integrity of the fibres, usually this is minor and recovery is rapid and complete. Fibres may be torn constituting a sprain, which is more severe and requires a longer healing period, fiber tearing may be partial or complete tear, the simple strain does not impair joint stability, all difficult sprains must be considered to have ligamentous damage impairing joint stability and thus must be probably treated, ${ }^{6.21 .22}$.

With the steady improvement of recording apparatus, nerve conduction studies have become a simple and reliable test of peripheral nerve function, the method has now been adequately standardized and widely used as a means of not only objectifying the lesion but also 
precisely localizing the site of maximal involvement, ${ }^{9.14 .20}$.

\section{Material and Methods \\ Subjects:}

Twenty patients with an ankle joint inversion trauma (8 males and 12 females) ranging in age from 30 to 45 years, selected from the out-patient clinics of Cairo University Hospitals. All patient received the same medical care and manual tests for the inversion trauma, they were subjected to the anterior drawer test, talar tilt test and the grading systems of Nicholas and Hershman, before the beginning of the study to select only the patients with grade II ankle sprain, (partial disruption or stretching of the ligament with some loss of function and joint instability), ${ }^{17.19}$.

Involved lower limbs were considered the experimental group, while the sound limbs were considered the control group for all the twenty patients.

\section{Instrumentation:}

\section{(A) The Amplaid EMG}

Electro diagnostic machine, that made by (Amplaid S.P.A in Milan, Italy) was utilized to obtain an objective evaluation of the common peroneal nerve MCV.

(B) The grading system of Nicholas and Hershman that was used to select only the patients with grade II ankle sprain to participate in this study include:

Grade I = Microscopic tearing of the ligament with no loss of function.

Grade II = Partial disruption or stretching of the ligament with some loss of function.

Grade III = Complete tearing of the ligament with complete loss of function, 16.18.

\section{Procedures:}

Motor conduction velocity recording technique was done in an air conditioned room, where a thermometer was available during whole experimental time to notice the ambient testing room temperature which was adjusted within a comfortable reasonable and narrow range between $24^{\circ} \mathrm{C}$ to $28^{\circ} \mathrm{C}$, and thus the temperature gradient along course of the tested nerve was minimized and the temperature - related variability was eliminated, ${ }^{12.23}$.

With the patient supine the active recording electrode was placed over the main bulk of the extensor digitorum brevis muscle (located in the anterolateral aspect of the proximal mid tarsal area), the reference electrode was placed distally over the small toe, while the ground electrode was placed over the medial potion of the foot, ${ }^{5.11 .14}$.

In the distal stimulation, the stimulating cathode was placed $8 \mathrm{~cm}$ proximal to the active recording electrode to provide a standardized distal latency segment, while in the proximal stimulation, the stimulation cathode was placed distally in the lateral part of the popliteal fossa (just medial to the biceps femoris tendon), ${ }^{13.14 .20}$.

\section{Data analysis}

Motor conduction velocity was measured for the first records, 10 days post trauma, and for the second records one month post trauma, in both groups. Collected data were fed into computer for the statistical analysis, descriptive statistics as mean, standard deviation, minimum and maximum, that were calculated for each group, the t-test was done to compare between the 2 groups and within each group. Alpha point of 0.05 was used as a level of significance.

\section{Results}

As shown in table (1) and figure (1), the mean value of the MCV for the first record in the experimental group was $(29.50 \pm 2.14) \mathrm{meter} / \mathrm{sec}$, while the mean value of the MCV for the second record in the same group was $(31.02 \pm 2.25)$ meter/sec, these revealed a non significant difference $(\mathrm{P}>0.05)$.

In the control group, the mean values of the $\mathrm{MCV}$ for both the first and second records were $(42.45+3.08) \mathrm{m} / \mathrm{sec}$, and $(42.80 \pm 3.11) \mathrm{m} / \mathrm{sec}$, respectively, and these results revealed also a non significant difference $(\mathrm{P}>0.05)$.

As observed in table (2) and figure (1), the mean values of MCV for the first 
records in both groups were $(29.50 \pm 2.14)$ and $(42.54 \pm 3.08)$ respectively, and these results revealed a highly significant difference $(\mathrm{P}<0.05)$.

Also, the mean values of MCV for the second records in both groups were $(31.02 \pm 2.25) \quad$ and $(42.80 \pm 3.11)$ respectively, and these revealed also a significant different $(\mathrm{P}<0.05)$.

Table (1): Motor conduction velocity of the experimental and control groups of the two records.

\begin{tabular}{||l|l|l|l|l|l|l||}
\hline & First record & \multicolumn{2}{|l|}{ Second record } & $\begin{array}{l}\text { Differ- } \\
\text { ence }\end{array}$ & $\begin{array}{l}\text { P. } \\
\text { value }\end{array}$ \\
\cline { 2 - 6 } & $\mathrm{X}$ & $\mathrm{SD}$ & $\mathrm{X}$ & $\mathrm{SD}$ & & $>0.05$ \\
\hline \hline $\begin{array}{l}\text { Experime } \\
\text { ntal } \\
\text { group }\end{array}$ & 29.50 & 2.14 & 31.02 & 2.25 & 1.52 & \\
\hline $\begin{array}{l}\text { Control } \\
\text { group }\end{array}$ & 42.45 & 3.08 & 42.80 & 3.11 & 0.35 & $>0.05$ \\
\hline \hline
\end{tabular}

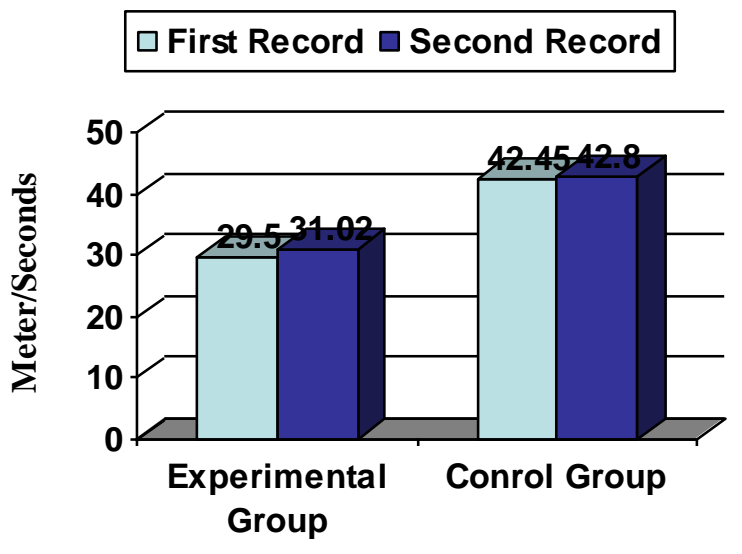

Patients Groups

Fig. (1): Mean values of MCV, of the 2 records in both groups.

Table (2): Comparison of the mean values of $\mathrm{MCV}$, between the 2 groups for each record.

\begin{tabular}{|c|c|c|c|c|c|c|}
\hline & \multicolumn{2}{|c|}{$\begin{array}{l}\text { Experiment } \\
\text { al group }\end{array}$} & \multicolumn{2}{|c|}{$\begin{array}{l}\text { Control } \\
\text { group }\end{array}$} & \multirow[t]{2}{*}{$\begin{array}{l}\text { Differ- } \\
\text { ence }\end{array}$} & \multirow{2}{*}{$\begin{array}{l}\text { P. } \\
\text { value }\end{array}$} \\
\hline & $\bar{X}$ & $\overline{S D}$ & $\bar{X}$ & SD & & \\
\hline $\begin{array}{l}\text { First } \\
\text { record }\end{array}$ & 29.50 & 2.14 & 442.45 & 3.08 & 12.95 & $\overline{c<0.05}$ \\
\hline $\begin{array}{l}\text { Second } \\
\text { record }\end{array}$ & 31.02 & 2.25 & 42.80 & 3.11 & 11.78 & $<0.05$ \\
\hline
\end{tabular}

\section{Discussion}

The study of nerve conduction velocity became an integral part of the electrodiagnostic assessment in the 1960s and the first international congress of EMG, was held at Pavia, Italy, in 1961, ${ }^{2.3 .11}$.

Conventional methods of nerve conduction study were mainly concerned with diseases affecting the distal portion of the peripheral nerve in the four extremities and seldom contributed to the investigation of the remainder of the nervous system, 1.2.3.11

The different classification systems used for grading severity of the ankle ligament injuries (especially the lateral ankle sprains), as those described by Nicholas and Hershman, McConkey and Leach, use the same terms to describe different phenomena, some use functional criteria to determine the grade, whereas others attempt to identify the type and degree of pathology present, so the used grading system must be defined for all clinicians treating the same patients, ${ }^{16.18}$.

The findings of the present study showed a significant difference in the first and second records between the mean values of the MCV of the experimental and control groups.

But comparison within the same group revealed a non significant difference. Significant differences showed in this study were in form of MCV reduction in the experimental group 10 days and one month post ankle - inversion trauma, were consistent with those observed and recorded by Long et al., 1991 ; Kleinrensink et al., 1994: Vleeming et al, 1995; and Mowafy et al., 1997.

A considerable contradiction was founded between results of MCV and the manually performed subjective tests for ankle inversion trauma as anterior drawer sign and talar tilt test, and little contradiction with the grading systems for ankle sprains evaluation, reflecting no correlation. So MCV measurements can be a valuable tool in assessing more objectively the functional instability of the ankle joint induced by inversion trauma. 


\section{Conclusion}

Motor conduction velocity objective measurement, in ankle joint inversion trauma can be considered as an additional useful tool to clinical evaluation.

\section{References}

1. Alexander IJ, Johnson KA: Reflex sympathetic dystrophy syndrome. In Disorders of the Foot and Ankle: Medical and Surgical Management, $2^{\text {nd }}$ ed (Jahss MH, ed). Philadelphia: WB Saunders, Pp 2187-2191, 1991.

2. Aminoff, M.J. : Electrodiagnosis in clinical neurology Churchill livingstone. New York. 1980.

3. Aminoff, M.J. : EMG in clinical practice. Addison-Wesley. New Jersy. 1978.

4. Ballantyne, J.P. and Campbell, M.J. : Electrophysiological study after surgical repair of sectioned human peripheral nerves. J. Neurol. Neurosurg. Psychiatry. 36:797. 1973.

5. Benecke, R. and Conrad, B. : The distal sensory nerve action potential as a diagnostic tool for the differentiation of lesions in dorsal roots and peripheral nerves. Neurology. 223:231. 1980.

6. Brahms MA: The small toes: Corns and deformities of the small toes. In Disorders of the Foot and Ankle: Medical and Surgical Management, $2^{\text {nd }}$ ed (Jahss MH, ed). Philadelphia: WB Saunders, pp 1175-1197, 1991.

7. D'Ambrosia RD, Zelis RF, Chuinard RO, et al: Interstitial pressure measurement in athletes with shin splints. Am J. Sports Med 5:127-131, 1977.

8. DeLacerda FG: Iontophoresis for treatment of shin splints. Orthop Sports Phys Ther 3:183-185,1982.

9. Jahss MH: Disorders of the hallux and the first ray. In Disorders of the Foot and Ankle: Medical and Surgical Management, $2^{\text {nd }}$ ed (Jahss MH, ed). Philadelphia: WB Saunders, 945-971, 1991.

10. Kalen V, Brecher A: Relationship between adolescent bunioas and flatfeet. Foot Ankle 8:331-336, 1988.

11. Kelikian H: Hallux Valgus, Allied Deformities of the Forefcot and Metatarsalgia. Philadelphia: WB Saunders, pp 213-225, 1965.
12. Kues J: The pathology of shin splints. J Orthop Sports Phys Ther 12:115-122, 1990.

13. Mann RA, Coughlin MJ: Lesser toe deformities. In Disorders of the Foot and Ankle: Medical and Surgical Management, $2^{\text {nd }}$ ed (Jahss MH, ed). Philadelphia: WB Saunders, pp 12051288, 1991.

14. Mann RA, Reynolds JD: Interdigital neuroma: a critical analysis. Foot Ankle 3:238, 1983.

15. Mann RA: Diseases of the nerves of the foot. In Surgery of the Foot, $5^{\text {th }}$ ed (Mann RA, ed ).St. Louis CV Mosby, pp 205-207, 1986.

16. O'Donoghue DH: Treatment of Injuries to Athletes. Philadelphia: WB Saunders, 1976.

17. Radin EL: Tarsal tunnel syndrome. Clin Orthop Relat Res 181:167-179, 1983.

18. Rana NA: Rheumatoid Arthritis, other collagen diseases, and psoriasis of the foot. In Disorders of the Foot and Ankle: Medical and Surgical Management, $2^{\text {nd }}$ ed (Jahss MH, ed)., Vol 3. Philadelphia : WB Saunders, pp 1719-1751, 1991.

19. Reiter H: As described by Solomon G in The Foot in Systemic and Acquired Disorders. In Disorders of the Foot and Ankle: Medical and Surgical Management, $2^{\text {nd }}$ ed (Jahss $\mathrm{MH}$, ed). Philadelphia: WB Saunders, 1991.

20. Scheuch PA: Tibialis posterior shin splint diagnosis and treatment. Athletic Trainging 19:271-274, 1984.

21. Scranton PE, Zuckerman JD: Bunions surgery in adolescents: results of surgical treatment. J Pediatr Orthop 4:69-43, 1984.

22. Solomon G: Inflammatory arthritis. In Disorders of the Foot and Ankle: Medical and Surgical Management, $2^{\text {nd }}$ (Jahss MH, ed). Philadelphia: WB Saunders, 1991.

23. Viladot A: The metatarsals. In Disorders of the Foot and Ankle: Mediacal and Surgical Management, $2^{\text {nd }}$ ed (Jahss MH, ed). Philadelphia: WB Saunders, pp 1229-12681991. 


\section{تأثير إصابة مفصل الكاحل الانقلابية على سرعة التوصيل

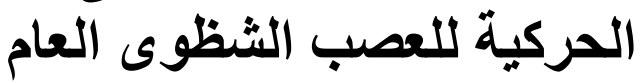

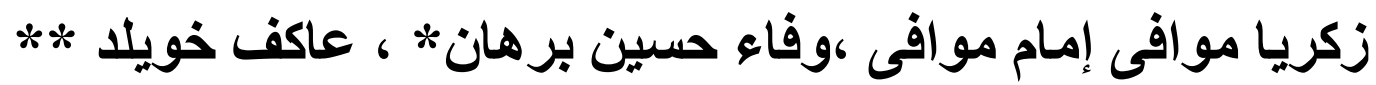

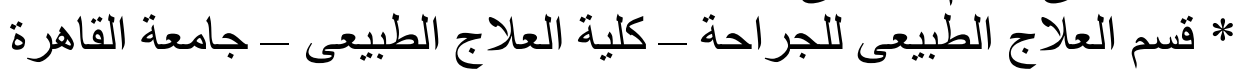

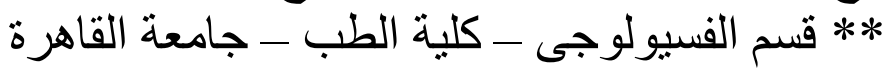

هدفت هذه الدر اسة إلى تحديد تأثير إصابة مفصل الكاحل الانقلابية على سر عة فئ

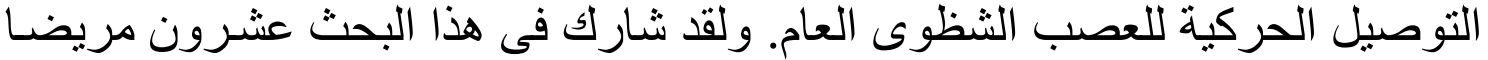

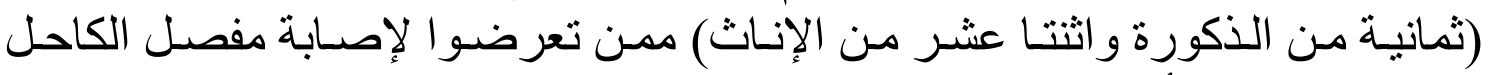

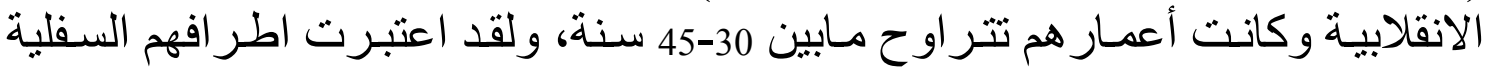

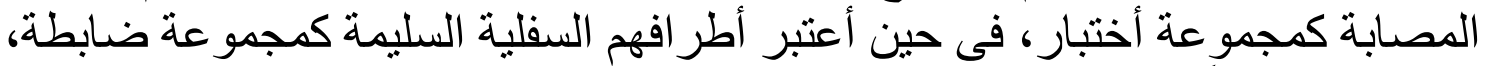

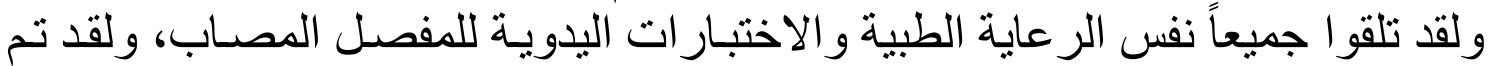

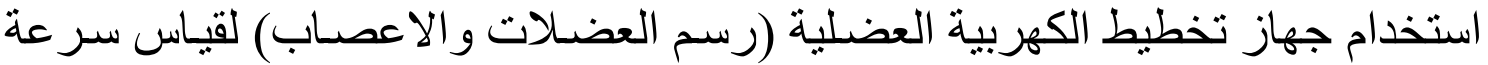

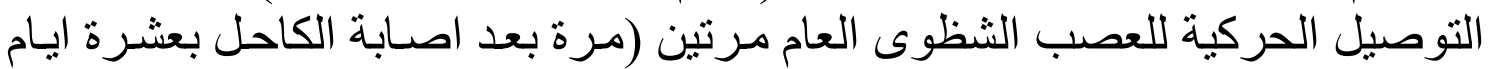

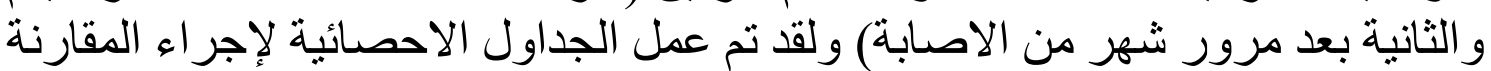

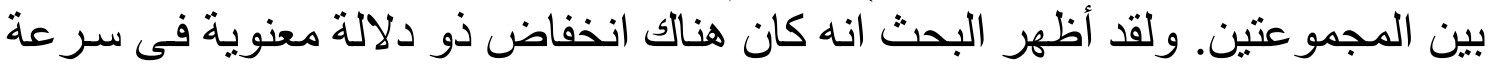

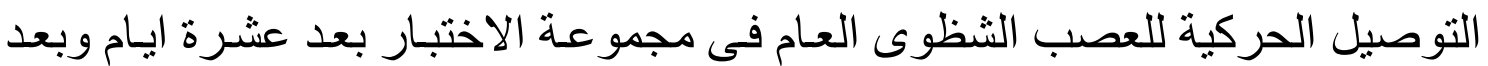

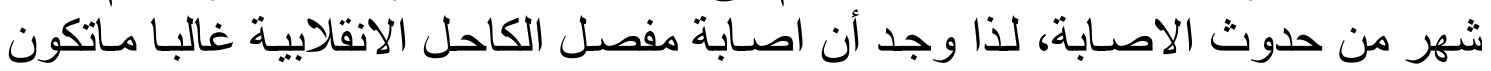

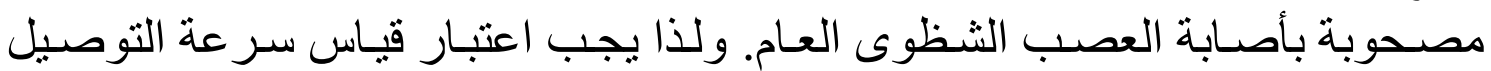

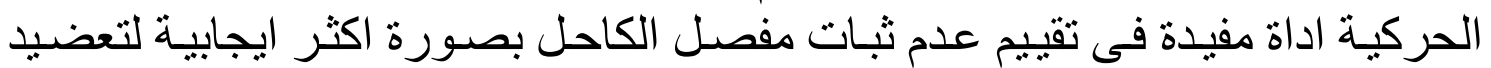

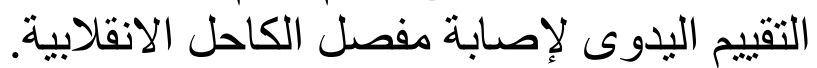

